\title{
A study on factors influencing use of standard precautions in the emergency department at BPKIHS, Dharan
}

\author{
BD Aryal, BK Rai, PP Gupta, S Giri, S Chaudhuri, AK Yadav \\ Department of General Practice \& Emergency Medicine \\ B.P. Koirala Institute of Health Sciences, Dharan, Nepal
}

\begin{abstract}
Background: This study investigated knowledge of and practices towards standard precautions, among all health care workers working in the emergency department in BPKIHS. Objective: To find out the factors influencing use of standard precautions in the emergency department, BPKIHS Dharan. Methods: This was a prospective observational study conducted in the emergency department. Data was collected in three ways: by direct observation of work practice, a questionnaire about knowledge, attitude and skills and through focus group discussions. Results: Regarding standard precaution, majority (54.2\%) had partial knowledge. Only $4.2 \%$ know the component of it. In practice $69.52 \%$ among doctors group washed hand even though once in four observations; $96 \%$ used soap. $43.80 \%$ used gloves in doctors group in four observation; sisters used gloves the entire times. 74\% washed hand after gloves removal (178). 35.23\% didn't recapped needles before disposal from those who used it among doctors group. Recapping is complete in sisters' group. 60.95\%. Sisters had complete proper disposal practice. Conclusion: Knowledge and practice of SP has direct impact in health of patient and HCW. High level of occupational exposure to blood highlights the urgent need for intervention to enhance occupational safety to prevent unnecessary nosocomial transmission of BBD. Strategies for promoting injection safety are necessary if the risk of nosocomial transmission of BBV via unsafe injection practice is to be minimized.
\end{abstract}

Keywords: Blood borne virus, infection control, standard precaution

\footnotetext{
Address for correspondence

Bijaya Devi Aryal

Department of GP \& EM

B.P. Koirala Institute of Health Sciences, Dharan

Email: bijaya.aryal@bpkihs.edu
} 


\section{Introduction}

Standard precautions combine the major features of universal precautions (UP) and body substance isolation (BSI) and are based on the principle that all blood, body fluids, secretions, excretions except sweat, nonintact skin, and mucous membranes may contain transmissible infectious agents ${ }^{1}$.

Standard precautions include a group of infection prevention practices that apply to all patients, regardless of suspected or confirmed infection status, in any setting in which healthcare is delivered to limit the risk of spread of blood borne viruses. In essence, the guidelines centre around safeguards aimed at reducing the risk of transferring blood borne virus. Staff come in contact with blood and body fluid of patients and thus faces a risk of acquiring human immunodeficiency virus (HIV) and Hepatitis "B" or "C". Infection. ${ }^{1}$ So it is important to make all health personnel aware of the modes of transmission of blood borne diseases and to help protect them from acquiring such types of infections.

In 1985, in order to increase awareness among health care workers of the danger of sharp injuries and other types of disease transmission, the center of disease control (CDC) and the occupational safety and health administration (OSHA) in the United States introduced the "universal precaution guidelines" which have been the worldwide standard in both hospital and community care setting $^{2}$

This study therefore aims to identify the knowledge and understanding of SP and the factors influencing use of SP and to make recommendations as to how these could be improved.

\section{Methods}

This prospective Observational study was conducted at Department of general practice and emergency medicine in B.P. Koirala Institute of Health Science, Dharan. This study included all the health care workers involved in emergency patient management.

A self-administered questionnaire was constructed, consisting of 3 parts. Part 1 consists of level of education, duration of work in BPKIHS \& type of education. Part 2 asked respondents if they had heard about "standard precaution" and measured knowledge of precautions, with 10 statements consists of knowledge of standard precaution. Part 3 investigated their practice towards standard precautions in 8 questions about use of protective devices, disposal of sharps, and decontamination of spills and used articles. The statements measuring knowledge of and practice towards Standard precautions based on the guidelines recommended by the CDC in 1996. The content validity of the questionnaire was assessed 
using the ideas of experts from the infection control committee of this hospital.

Focus group discussion was done for factors influencing use of SP in emergency department. Three focus groups (health aides, nurses and doctors) were conducted, 9 participants were chosen from each group. They were asked for the recommendation that could improve use of standard precaution, \& what could be done to implement these. Group members were randomly chosen from the list of staff head category and asked if they would participate.

Direct observation was done in the emergency department looking for: hand washing, sharps recapping \& disposal and use of protective garments including gloves, spending 1-2 hours a day, at different times of a day. The staffs observed were chosen as a convenience sample, depending on who was present at the time, and each person was observed on one occasion only. Hand washing was measured by observing the proportion of times staff washed between patients. Spot checks were also being carried out weekly for 3 months to observe whether soap and towel were available.

One hundred incidences of sharps disposal were observed and the proportion in which this was safely carried out was recorded. Spot checks were carried out weekly for 3 months on the availability of suitable sharps containers. Staff was requested to report all incidents of needle stick injury during the study period, to the researcher as well as their supervisor. One hundred encounters during which gloves should be worn according to the SP guidelines were observed and usage recorded. Weekly checks were made at different times of day on availability of gloves.

Results was entered into excel database and reported in percentage terms, stratified by role (doctors, nurses, and health aid). Focus Groups Discussion was recorded and then analyzed for important themes and recommendations. The data were analyzed using SPSS 12.0 Software programme.

\section{Results}

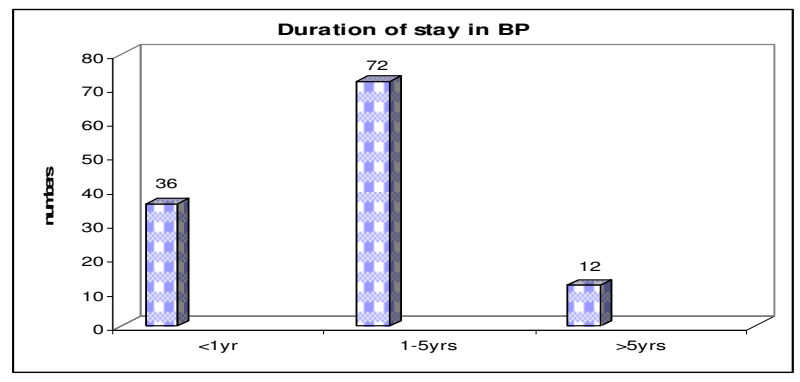

Number of participants with respect to duration of stay in BPKIHS $(n=120)$.

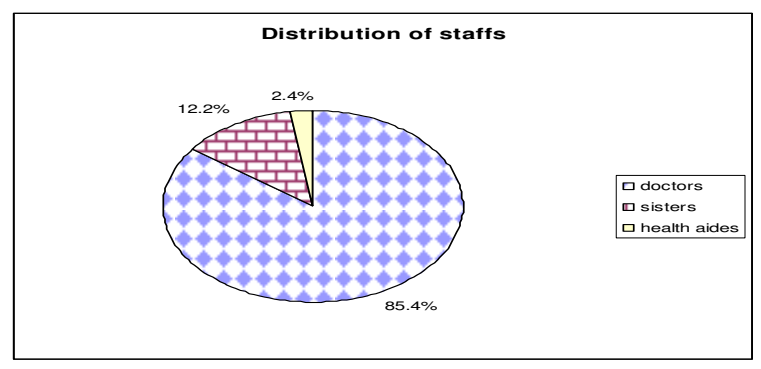

Distribution of staffs participated in this study 


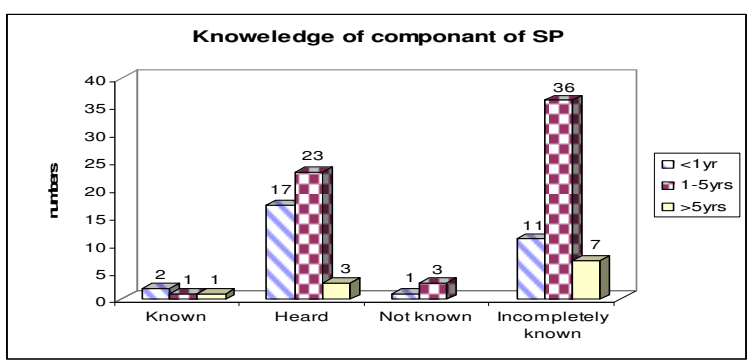

Knowledge of component of SP (hand washing, wearing gloves, wearing protective gowns, mask \& goggles, proper disposal of needle) among Doctors group with respect to duration of stay at BP $(n=105)$

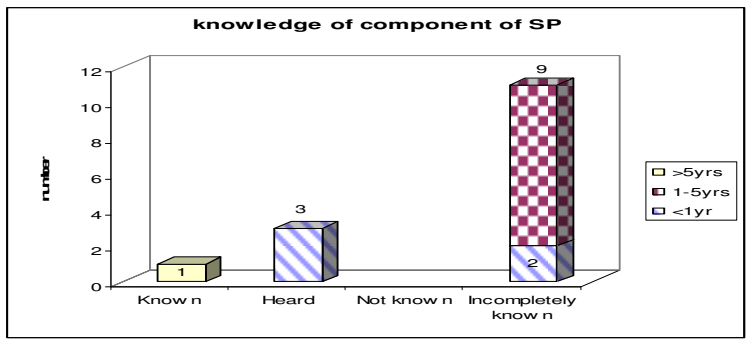

Knowledge of component of SP among nursing staff with respect to duration of stay at $B P(n=15)$

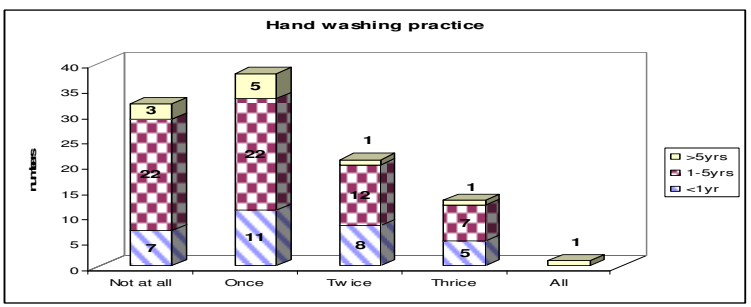

Results of practice of SP from direct observation.

Hand washing practice after examining patient in doctors group (each Dr. observed for 4 patients) with respect to duration of stay in BPKIHS $(n=105)$

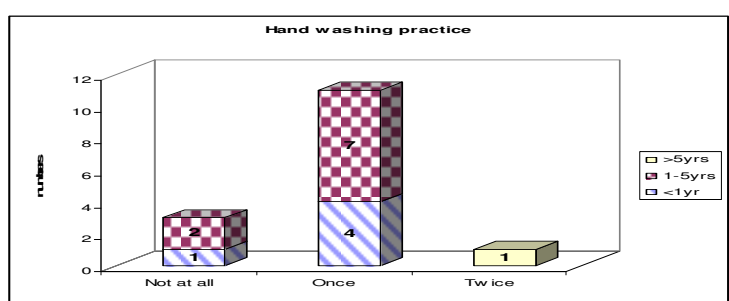

Hand washing practice after examining patient in nursing staffs group with respect to duration of stay in BPKIHS $(n=15)$

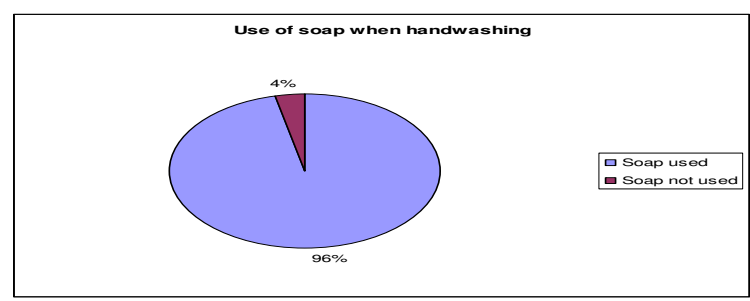

Proportion of times soap used during hand washing $(n=130)$

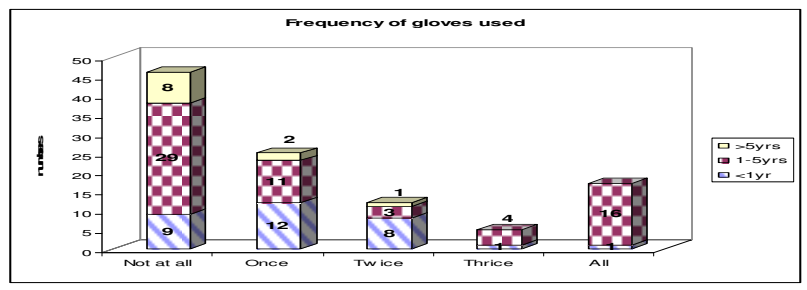

Total gloves used in examining patient (4 observations) with respect to duration of work in doctors group $(n=105)$

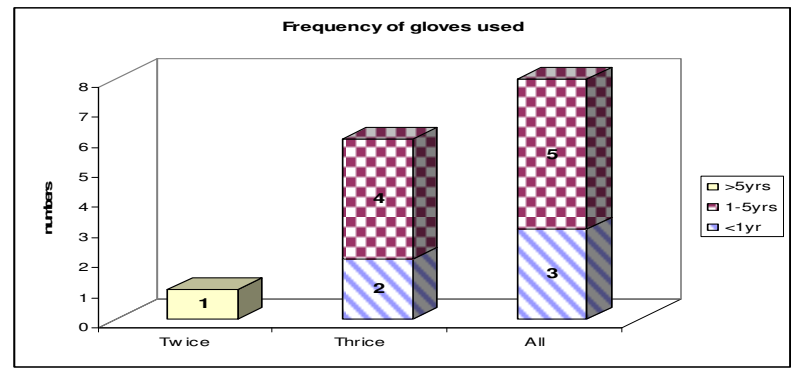

Total gloves used in examining patient (4 observations) with respect to duration of work in nursing staffs group $(n=15)$ 


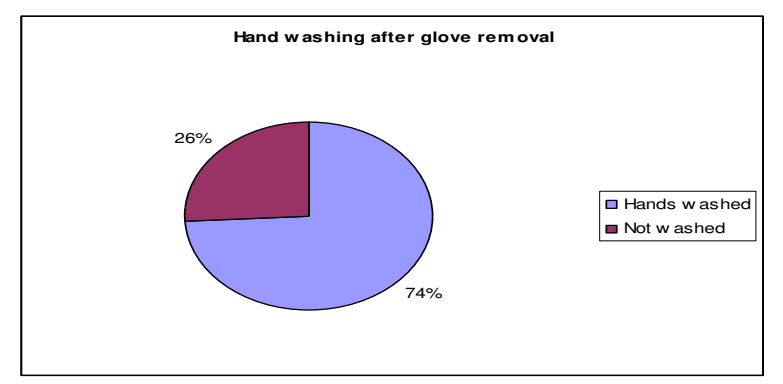

Observation of frequency of hand washes after removal of gloves among those wearing gloves. (178 instances of glove wearing)

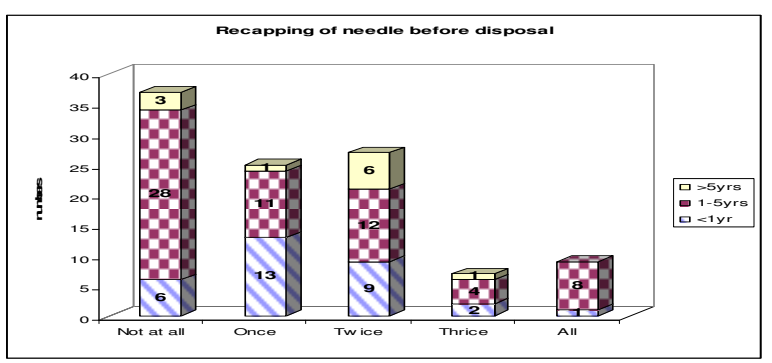

Practice of recapping of needle before disposal in doctors group from those who used it. (4 observations of needle use for each doctor) $(n=105)$

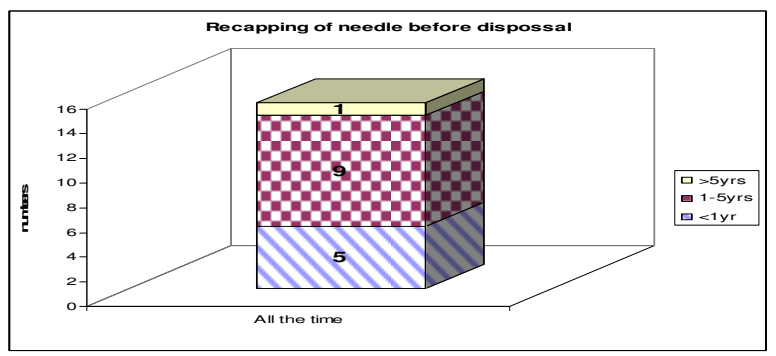

Recapping of needles from those who used it- nursing staffs group $(n=15)$

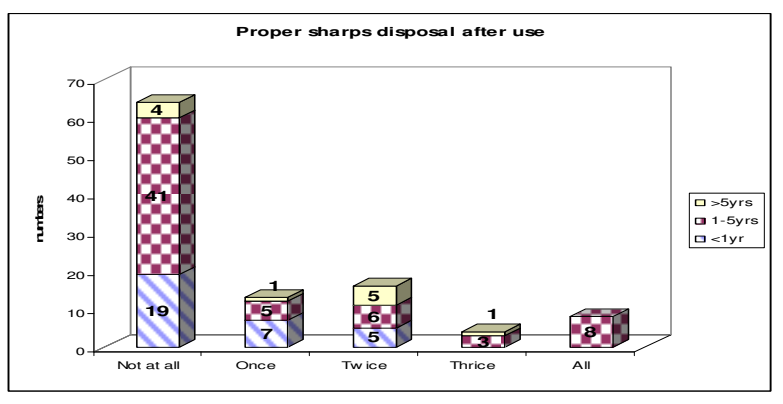

Proper disposal of sharps after use with respect to duration of work in BPKIHS in doctors group. (4 observations of needle disposal for each doctor) $(n=105)$

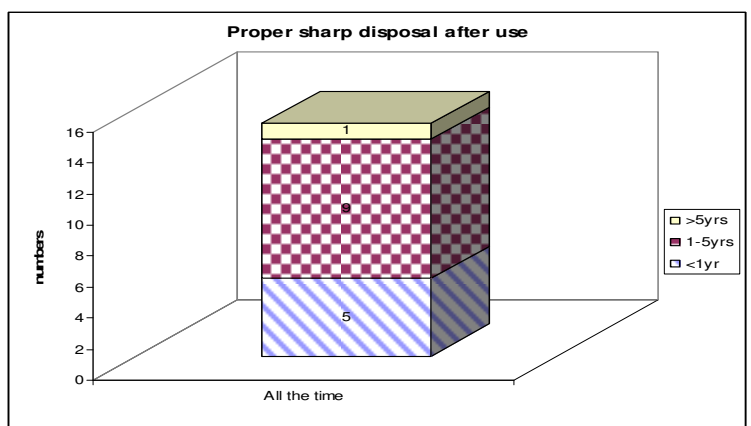

Proper disposal of used needles with respect to duration of stay in BPKIHS- nursing staffs group (4 observations for each nurses). $(n=15)$

Comparative results of Knowledge and practice of SP

\begin{tabular}{|l|l|l|}
\hline & Knowledge & Practice \\
\hline Hand washing & $82.5 \%$ & $29.16 \%$ \\
\hline Glove use & $75.8 \%$ & $38.33 \%$ \\
\hline Protective gown & $20.2 \%$ & $\begin{array}{l}\text { Not } \\
\text { available }\end{array}$ \\
\hline Mask & $79.1 \%$ & $\begin{array}{l}\text { Not } \\
\text { available }\end{array}$ \\
\hline Either not & $22.5 \%$ & $30.8 \%$ \\
\hline
\end{tabular}




\begin{tabular}{|l|l|l|}
\hline $\begin{array}{l}\text { recapping or } \\
\text { using one-handed } \\
\text { recapping }\end{array}$ & & \\
\hline $\begin{array}{l}\text { Proper sharp } \\
\text { disposal }\end{array}$ & $70 \%$ & $19.2 \%$ \\
\hline
\end{tabular}

Results of observation in emergency for availability of towel, soap, water supply, gloves and sharp box

During spot check, it was found that half of the time (25/48), the emergency department doesn't have gloves. If they are available, it is mostly in the morning time, less in other part of a day.

Emergency department has towel all the time in spot check (12/12), but regarding soap it is available most of the time (10/12). Emergency has adequate supply of water (48/48).

There are adequate supplies of sharp box near working area. In most of the time we found that sharp box was empty to half filled (48/48) Sometimes, we found those needles are sticking outside from sharp box even though it is not filled (40/48)

Emergency department doesn't have any supply of protective gowns, apron and mask.

\section{Focus group discussion}

Venue: BPKIHS Auditorium

Targeted population: Doctors of various departments, sisters \& health aid
Focus group discussion was done regarding factors influencing use of S.P in the emergency department. From this discussion we came to know the knowledge and attitude of SP. Although they were aware of prevention of transmission of disease, they are not applying because of rush in emergency, lack of adequate man power allocated, lack of senior personnel in busy emergency; unavailability of adequate gloves and lack of mask, apron, eight out of nine doctors are aware of hand washing for prevention of transmission of disease from patient to doctor; doctor to patient and patient to patient. So they usually wash hand after contact with blood and body secretion. Regarding hand washing they won't get soap always 2/9 times in emergency. But has adequate supply of water and towel for drying hand. If they won't get soap 2/9 said that they complains, 2/9 wash with plain water, 3/9 use spirit for disinfection and 2/9 go to respective ward for hand washing for those who have plenty of time.

Regarding PPE; only gloves is available in $E R$, so all recommend that this should be available for effective adherence to SP.

All recommend that the emergency department must have adequate supply of soap, and disinfectant. It must have adequate gloves and mask. Hospital should have adequate doctors and related staffs so that 
everyone can be strict for SP, which prevents transmission of disease.

In conclusion we found that emergency department has inadequate supply of gloves and no supply of protective gowns, goggles, mask and boots. For effective application of standard precaution these protective supply should be made available in our emergency department.

\section{Discussion}

The present study investigated the factors influencing use of Standard Precautions in the Emergency Department of B.P.Koirala Institute of Health Sciences, Dharan. This study mainly focused on How far the knowledge of Standard Precautions is translated into correct practice in practical setting and also determined the factors that hinders in utilizing Standard precautions into practices.

In the present survey, knowledge of the components of SP is more among those who had worked for 1-5yrs, even though incompletely in doctors group. In nursing group complete knowledge is found in those who stayed longer (5yrs), among whom all were aware of components of SP. This difference may be due to not involving such topics in curriculum and not giving any training to doctors' population. For nurses, institute provide refresher course for them so knowledge is increased in increasing duration of stay.

Comments like "in this busy department washing hand before examining every patient, changing gloves for every patient is not feasible, we have limited gloves available in emergency, rush emergency department, limited numbers of staffs in comparison to patients made using personal protective equipment very difficult, and more or less similar remarks highlighted the reasons for non-compliance.

Study done in INF Pokhara showed that trained HCWs displayed good knowledge compared to untrained HCW. About $86 \%$ were aware of the need to take precaution while providing care, However correct knowledge of SP was lacking in both the group.

Study done in Tertiary care referral center (published in Ann Intern Med 1998 Sep 1; 109(5):394-8) Infection Control Program at the University of Geneva Hospitals showed that it may not be prudent to wash and reuse gloves between patient. Further hand washing is strongly encouraged after removal of gloves. Among reasons reported for poor adherence with hand hygiene recommendations, some that are clearly related to the institution (i.e., the system) include lack of institutional priority for hand hygiene, need for administrative sanctions for noncompliance or rewards for compliance, 
and lack of an institutional climate that encourages safety.

Article published in American journal of Epi. Science documented that $10 \%-25 \%$ injuries occurred while recapping a used needle. The recapping of needle has been prohibited under the occupational safety and Health Administration (OSHA) blood-borne pathogen standard ${ }^{10}$ In our study 22 out of 36 (61.0\%) were of the impression that needle should be recapped after use (<1yr), 58/72 (80.5\%) in 1-5yrs stay. Regarding methods of recapping just over half know they should use a one handed technique.

Our results are therefore similar to those from a study done in Kathmandu medical college and teaching hospital which showed that $4 \%$ and $61 \%$ of the health care workers, respectively, were unaware of the fact that hepatitis $B$ \& $C$ can be transmitted by needle stick injury. 55(79\%) were of the impression that needle should be recapped after use, while no one had adequate knowledge of new needle device and the safety feature ${ }^{7}$.

From focus group, all recommended that adequate numbers of doctors \& nurses should be present for effective implementation of SP.Lack of adequate gloves in emergency is the major factors in not using it; so adequate gloves should be there in working area.

The direct cost of SP is high. Study done by Doebbeling et al in 1990 '; showed that following the institution of SP, use of rubber gloves increased from 1.64 million pairs of 2.81 million pairs annually. Total annual costs for isolation materials increased by $\$ 350,900$. This represented an increase from $\$ 13.70$ to $\$ 22.89$ per admission (60\%). The cost of isolation materials increased from $\$ 98$ to \$215 per 1000 outpatient visits, an adjusted increase of $92 \%$. ${ }^{8}$ The cost of sterile gloves here is around NRS 20 for each pair, whereas for non sterile it costs around NRS 10 if bought in wholesale rate. So the cost of SP is high if implemented properly.

Knowledge alone is often not sufficient however. All staff acknowledged that they didn't always put SP into practice for reasons such as rush of emergency department; lack of adequate manpower; unavailability of mask and protective gowns, decreased supply of gloves. Systemic factors enabling use of SP are good water supply and presence of soap $^{22-26}$.

To improve practice as well as knowledge, systemic factors, particularly glove supply, and sharps containers, will also need to be addressed. This will increase the costs of running the department, but is important for staff safety.

\section{Conclusion}

Standard precautions are intended to be applied to every patient encounter where there is potential for exposure to blood or 
body fluids. This is not happening, at least some of the time. The biggest danger areas for our staff stem from not wearing gloves, and from recapping needles. To address these problems, further education will be needed. For instance the majority of nurses regarded recapping of needles as safest practice.

\section{References}

1. Centre for disease control (CDC) (1998) update: Universal precautions for prevention of transmission of HIV, HBV and other blood borne pathogens in health setting. MMWR (morbidity and mortality weekly report) 37(24): 377 .

2. Guidance for clinical healthcare workers: protection against infection with bloodborne viruses. London: UK Health Departments, 1998; Available on www.hpa.org.

3. Kermode Michelle; Jolley Damien; Langkham Biangtung; et al: compliance with SP among Health care worker in rural India. American journal of infection control; 2005; 33(1): 27-33.

4. US department of labor. Occupational safety and health administration www.osha.gov Accessed on 28.1.07.

5. Uranw SK, Alam S. A correlative study between knowledge and practice of UP among staff nurse working at the BPKIHS. Dharan. Research report
2000. Done by B.Sc. nursing.

6. Visser HJ, Timilshina N, Dayal V, Rai B. Int. conf AIDS. 2004 Jul 11-16; 15: abstract no. D12233. HIV/AIDS Knowledge, attitude and practice among trained and untrained basic health workers in Nepal.

7. Gurub Acharya DL, Mathura KC, Karki DB. Knowledge, attitude and practices among health care workers on needlestick injuries. Kathmandu University Medical Journal 2003; 1(2): 91-94.

8. Doebbeling BN, Wenzel RP. The direct cost of Universal precautions in a teaching hospital. 1990; 264(16):20837.

9. Ruben FL, Norden CW, Rockwell K, Hruska. Epidemiology of accidental needle puncture wounds in hospital workers. American journal of Epi. Science 1983; 228: 26-30.

10. Occupational safety and health administration: final rule on occupational exposure to blood borne pathogen. 56 Fed Reg. 64004 (1991) [cited 20.1.07]; Available on www.osha.gov.

11. Odujinrin OM, Adegoke OA. AIDS; Awareness and blood handling practices of health care workers in Lagos, Nigeria. Eur J Epidemiol. 1995; $11(4): 425-30$. 
12. Knight VM, Bodsworth NJ. Perceptions and practice of universal blood and body fluid precautions by registered nurses at a major Sydney teaching hospital. J Adv Nurs.1998; 27(4):74651.

13. Dargen $P$, Thakur S. Jain B K, Singh R, Deb M. Awareness and practice of universal precautions by health care worker in a teaching institute, JNMA, July-September, 2001; 40.

14. American Dental Association. Infection control, its evolution to the current standard precaution. J Am D Assoc 2003; 134(5): 569-574.

15. Universal precautions including injection safety. 2007 [cited 18.1.07]; available from

www.who.inthiv/topics/precautions/univer sal /en.

16. Kermode M, Holmes W, Langkham B, Thomas MS, Gifford S. HIV-related knowledge, attitudes and risk perception amongst nurses, doctors and other healthcare workers rural India. Indian J Med Res. 2005; 122(3):258-64.

17. Obi SN, Waboso P, Ozumba BC. HIV/AIDS: Occupational risk, attitude and behavior of surgeons in southeast Nigeria. Int. J. STD AIDS, 2005; 16(5):370-3.
18. Glenn LL, Ramsay PW. Universal precautions compliance and exposure frequency to patient body fluids in nurses employed by urban and rural health care agencies. Journal of Rural Health 1995; (3):158-168.

19. Thakur S. Awareness and practice of universal precautions by health care worker at BPKIHS, A research report 1998.

20. Molinari AJ. Infection control, its' evolution to the current standard precautions. J Am D Association 2003; 134(5): 569-574.

21. Royal college of nursing. Universal precautions against hepatitis and AIDS. London: Royal college of Nursing; 1994.

22. Heath H. (editor) Potter \& Perry's foundation in Nursing theory and practice. London: Mosby; 1996.

23. Tietjen L, Bossemeyer D, Mcintosh $\mathrm{N}$. Prevention: Guidelines for Health care facilities with limited resources. JHPIEGO Corporation, Baltimore, March 2003. Accessed Jan 07 on: http://www.reproline. jhu.edu/english/4morerh/4ip/ipmanual/ip manual.ntm.

24. Whitehouse JD, Sexton DJ, and Kirkland KB. Infection control: Past, present \& future issues. Comprehensive therapy 1998; 24(2):71-77. 
25. Hospital-acquired infections; guidelines for control BPKIHS, Dec.2002.

26. Doheny $\mathrm{KI}$. Simple measures reduce bloodstream infections. Health day news Dec.27 2006 [cited 15.1.07]; available from: www.healthday.com. 